\title{
Association between pre-miR-27a functional polymorphism and risk of colorectal cancer in north Chinese Han population
}

This article was published in the following Dove Press journal:

OncoTargets and Therapy

19 October 2015

Number of times this article has been viewed

\author{
Quan Bian ${ }^{1, *}$ \\ Jian-Jun Chen ${ }^{2, *}$ \\ Jun-Ping $\mathrm{Gu}^{\prime}$ \\ Jing $X u^{3}$
}

'Department of General Surgery, Tianjin Hospital, Tianjin, ${ }^{2}$ Department of General Surgery, Beijing Chaoyang Hospital, Beijing, ${ }^{3}$ Department of Gastrointestinal Surgery, Union Medical Center of Tianjin, Nankai University Affiliated Hospital, Tianjin, People's Republic of China

*These authors contributed equally to the study
Correspondence: Quan Bian Department of General Surgery, Tianjin Hospital, 406 South Road of Jiefang, Tianjin, People's Republic of China Tel/fax +86 02260910608

Email bianquantjyy@163.com

Jing Xu

Department of Gastrointestinal Surgery, Union Medical Central of Tianjin, Nankai University Affiliated Hospital, I 30 West Jieyuan Road, Tianjin, People's Republic of China

Tel/fax +86022 87729595

Email jingxutj@yeah.net

\begin{abstract}
MicroRNA-27a (miR-27a) is deemed as an oncogene in malignancies including colorectal cancer (CRC), and rs895819 within pre-miR-27a may affect its secondary structure, leading to its aberrant expression and dysfunction of its targeted gene. We investigated genotype and allele frequencies of the locus in 412 I-III stage CRC cases and 412 age- and sex-matched healthy individuals to explore the possible association between them in the north of Chinese population. The results showed that frequencies of alleles $\mathrm{A}$ and $\mathrm{G}$ and genotypes GG, AG, and AA of the locus were $65.7 \%, 34.3 \%, 17.0 \%, 34.7 \%$, and $48.3 \%$ in cases and $69.9 \%, 30.1 \%, 9.9 \%, 40.2 \%$, and $49.8 \%$ in controls, respectively. GG genotype of the locus was positively associated with an increased risk of CRC in codominant ( $P=0.01$, adjusted odds ratio $=1.541,95 \%$ confidence interval $=1.110-2.239$ for genotype GG vs AA) and recessive $(P=0.003$, adjusted odds ratio $=1.855,95 \%$ confidence interval $=1.221-2.786$ for genotype $\mathrm{GG}$ vs AA/GA) models, indicating that GG genotype of the locus might increase susceptibility to CRC. Moreover, genotypes AG and GG and allele $\mathrm{G}$ were significantly associated with III stage ( $P<0.001, P<0.001$, and $P=0.001$, respectively), suggesting that the locus was associated with the progression of CRC. These results suggested that rs 895819 within pre-miR-27a was involved in colorectal carcinogenesis and progression, genotype GG of the locus might be a susceptible factor for CRC, and allele $\mathrm{G}$ and allele $\mathrm{G}$ carrier (genotypes AG and GG) could predict CRC progression in north Chinese Han population.
\end{abstract}

Keywords: miR-27a, polymorphism, colorectal cancer

\section{Introduction}

Colorectal cancer (CRC) is a kind of complicated disease that severely affects human health worldwide. According to a report conducted by Siegel et al $^{1}$ in 2015, 132,700 individuals will be diagnosed as new CRC cases and 49,700 individuals will die due to the disease in the USA. Meanwhile, 2015 People's Republic of China cancer report showed that there were 310,244 newly diagnosed CRC patients and 149,722 dead CRC cases in $2011 .^{2}$ Although there is a rapid advance in the research of CRC initiation and progression mechanisms, the cause of a large proportion of the cases remains unclear. . $^{3,4}$ It is well known that the disease is initiated by an intense cross talk of genetic and environmental factors. ${ }^{5}$ Emerging studies showed that genetic variations of related genes were significantly associated with risk and clinical outcome of the disease. ${ }^{6-8}$

MicroRNA-27a (miR-27a) is an oncogene in malignancies including CRC. ${ }^{9}$ It is located in 19p13.13 containing an exon and the transcript is a 22 nucleotide noncoding RNA. Overexpression of hsa-miR-27a was examined in laryngeal carcinoma, osteosarcoma, hepatocellular carcinoma, CRC, and many kinds of cell lines, such 
as HepG2, Bel-7402, Bel-7404, SW480, and HT29 cell lines. ${ }^{10-14}$ Moreover, it was involved in cell proliferation, cell cycle transition and apoptosis, colony formation, migration, and metastasis in cancer cell line. ${ }^{11,12}$ Additionally, it mediated a poor response to chemotherapy in esophageal squamous cell carcinoma, leukemia, lung adenocarcinoma, gastric cancer, and SW480 cell lines. ${ }^{14-17}$

Rs895819 is a common single nucleotide polymorphism (SNP) locating in pre-miR-27a. Alternation from A to G of the locus may contribute to its abnormal secondary structure and aberrant expression of hsa-miRNA-27a, leading to dysfunction of hsa-miRNA-27a or aberrant expression of its targeted gene. Some case-control studies have been carried out to investigate the association between the locus and risk of cancer. ${ }^{18-21}$ Xiong et $\mathrm{al}^{21}$ reported that allele $\mathrm{A}$ and genotypes AG and AA of the locus were associated with a decreased risk of cervical cancer. Whereas studies conducted by $\mathrm{Ma}$ et $\mathrm{a}^{20}$ and $\mathrm{Xu}$ et $\mathrm{a}^{22}$ indicated that there was a positive association between the locus and susceptibility to nonsmallcell lung cancer and digestive tract cancer, respectively. So we hypothesize that rs895819 within pre-miR-27a may be involved in the carcinogenesis of CRC.

Hence, we investigated allele and genotype frequencies of the locus in 412 I-III stage CRC cases and 412 age- and sex-matched healthy individuals using Taqman-polymerase chain reaction (PCR) to explore the possible association between them in north Chinese population.

\section{Materials and methods}

A total of 412 clinical pathological confirmed CRC patients and 412 age- and sex-matched healthy checking-up participants, from May 2009 to December 2014 in Union Medical Center of Tianjin, Nankai University Affiliated Hospital, were included in our study. All enrolled individuals were Chinese Han population, which consisted of $>95 \%$ of the population in the People's Republic of China. All controls were free of cancer clinical symptom, and serum CEA was $<5 \mu \mathrm{g} / \mathrm{L}$. Human genomic DNA of each participant was extracted from $200 \mu \mathrm{L}$ ethylenediaminetetraacetic acid-anticoagulated peripheral blood samples using Qiagen human genomic DNA isolation kit (Qiagen NV, Venlo, Netherlands) according to the manufacturer's protocol. Ultraviolet spectrophotometer (Eppendorf, Hamburg, Germany) was used to detect DNA concentration and purity of each sample, and A260/A280 ratio should be within the interval of 1.8-2.0. Genotype of rs895819 was detected by Taqman discrimination assay using ABI7300 fluorescence quantitative PCR system (Thermo Fisher Scientific, Waltham, MA, USA). The detection was performed in a total volume of $5 \mu \mathrm{L}$ that contained $100 \mathrm{ng}$ genomic DNA temple, $2.5 \mu \mathrm{L} 2 \times$ TaqMan PCR MasterMix, and $2.5 \mu \mathrm{L} 20 \times$ SNP Assay (including primer and FAM/VIC: Carboxyfluorescein/Victoria probe). rs895819 primer and probe sequences and reaction conditions were used according to the description by $\mathrm{Xu}$ et $\mathrm{al}^{23}$ and 5\% PCR products were randomly selected to DNA sequencing. All written informed consents were signed by all included individuals, and the study was approved by the ethical committee of Union Medical Center of Tianjin, Nankai University Affiliated Hospital.

We directly counted the allele and genotype distributions of rs895819 in two groups. Hardy-Weinberg equilibrium (HWE) software (http://www.oege.org/software/hwe-mrcalc.shtml) was used to evaluate whether the genotypes of the locus fit for HWE in controls. Personal $\chi^{2}$-test was used to examine the allele or genotype distribution difference in the two groups. Odds ratio (OR) and 95\% confidence interval ( $95 \% \mathrm{CI}$ ) were calculated to evaluate the strength between the locus and risk of CRC. $P<0.05$ was considered as a significant difference in all statistics. All the data analyses were conducted using SPSS 19.0 statistical software (IBM Corporation, Armonk, NY, USA).

\section{Results}

The baseline characteristics of the two groups were shown in Table 1. However, no significant difference was observed in terms of age, sex, smoking, and drinking between the two groups. The details of the rs 895819 allele and genotype frequencies in the two groups were listed in Table 2. The locus genotype frequencies of AA, AG, and GG in the controls were $49.8 \%, 40.2 \%$, and $9.9 \%$, respectively. The frequency distribution was similar with the report in dbSNP database (http:// www.ncbi.nlm.nih.gov/projects/SNP/snp ref.cgi?rs=895819) in Chinese Han population, and the controls' genotype distribution was consistent with $\operatorname{HWE}\left(\chi^{2}=0.742, P=0.388\right)$.

The frequencies of genotypes AA, AG, and GG and alleles $\mathrm{A}$ and $\mathrm{G}$ of rs895819 were $48.3 \%, 34.7 \%, 17.0 \%, 65.7 \%$, and $34.3 \%$ in cases and $49.8 \%, 40.2 \%, 9.9 \%, 69.9 \%$, and $30.1 \%$ in controls, respectively. There was no significant genotype frequency difference in comparison of AG vs AA (34.7\% vs 40.2\%, $P=0.43$, adjusted $\mathrm{OR}=0.871,95 \% \mathrm{CI}=0.676-1.131$ ) or allele G vs A $(34.1 \%$ vs $30.1 \%, P=0.065$, adjusted $\mathrm{OR}=1.247,95 \%$ $\mathrm{CI}=0.913-1.652$ ), suggesting that genotype $\mathrm{AG}$ and allele $\mathrm{G}$ of the locus were not associated with CRC. There was no significant frequency difference in dominant model (AG/GG vs AA: 51.7\% vs $51.2 \%, P=0.676$, adjusted $\mathrm{OR}=1.210,95 \% \mathrm{CI}=0.754-1.524$ ) or overdominant model (AA/GG vs AG: $65.3 \%$ vs $59.8 \%$, $P=0.098$, adjusted $\mathrm{OR}=0.810,95 \% \mathrm{CI}=0.632-1.232$ ). Whereas 
Table I Baseline characteristics of the cases and controls

\begin{tabular}{|c|c|c|c|c|c|}
\hline Variables & Cases (4I2) & Percentage & Controls (4I2) & Percentage & $P$-value \\
\hline Age (years, M + SD) & $61.2 \pm 10.5$ & & $61.2 \pm 10.5$ & & $>0.05$ \\
\hline \multicolumn{6}{|l|}{ Sex } \\
\hline Male & 293 & 71.10 & 293 & 58.50 & $>0.05$ \\
\hline Female & 119 & 28.90 & 119 & 41.50 & \\
\hline \multicolumn{6}{|l|}{ Smoking } \\
\hline Yes & 105 & 25.50 & 89 & 21.60 & 0.954 \\
\hline No & 307 & 74.50 & 333 & 78.40 & \\
\hline \multicolumn{6}{|l|}{ Drinking } \\
\hline Yes & 113 & 27.40 & 101 & 24.51 & 0.965 \\
\hline No & 301 & 72.60 & 311 & 75.49 & \\
\hline \multicolumn{6}{|l|}{ Location } \\
\hline Right colon & 210 & 51.00 & & & \\
\hline Left colon & 97 & 23.54 & & & \\
\hline Rectum & 105 & 25.46 & & & \\
\hline \multicolumn{6}{|l|}{ Differentiation } \\
\hline High/moderate & 332 & 80.58 & & & \\
\hline Poor/undifferentiated & 80 & 19.41 & & & \\
\hline \multicolumn{6}{|c|}{ Tumor-Node-Metastasis (TNM) } \\
\hline $\mathrm{I} / \mathrm{II}$ & 287 & 69.66 & & & \\
\hline III & 125 & 30.34 & & & \\
\hline \multicolumn{6}{|l|}{ Cancer invasion } \\
\hline $\mathrm{TI} / \mathrm{T} 2$ & 90 & 21.84 & & & \\
\hline $\mathrm{T} 3 / \mathrm{T} 4$ & 322 & 78.16 & & & \\
\hline \multicolumn{6}{|l|}{ Node metastasis } \\
\hline No/NI & 89 & 21.60 & & & \\
\hline $\mathrm{N} 2 / \mathrm{N} 3$ & 323 & 78.40 & & & \\
\hline
\end{tabular}

Abbreviations: $M$, mean; SD, standard deviation.

significant frequency differences were examined in comparison of GG vs AA ( $17.0 \%$ vs 9.9\%, $P=0.01$, adjusted $\mathrm{OR}=1.541$, $95 \% \mathrm{CI}=1.110-2.239)$ and in recessive model ( $17.0 \%$ vs $9.9 \%$, $P=0.003$, adjusted $\mathrm{OR}=1.855,95 \% \mathrm{CI}=1.221-2.786$ for genotype GG vs AA/GA).

The relationship between clinical pathological characteristics and rs895819 was shown in Table 3. As shown from Table 3, there was no significant difference of rs895819 genotype and allele frequency distributions in the subgroups of clinical pathological characteristics, such as CRC location, differentiation, invasion, and node metastasis. However, genotypes AG $(P<0.001)$ and $\mathrm{GG}(P<0.001)$ and allele $\mathrm{G}$ $(P=0.001)$ of the locus were significantly associated with TNM-III stage in our study, respectively.

\section{Discussion}

miRNA is a group of noncoding RNA that plays a powerful role both in organ growth and development, cell proliferation,

Table 2 Genotype and allele distributions of rs895819 in two groups

\begin{tabular}{|c|c|c|c|c|c|c|}
\hline Model & Genotype and allele & Cases & Controls & $P$-value & OR and $95 \% \mathrm{Cl}$ & Adjusted OR and $95 \% \mathrm{Cl}^{\mathrm{a}}$ \\
\hline \multirow[t]{3}{*}{ Codominant } & $\mathrm{AA}$ & 199 (48.3\%) & $205(49.8 \%)$ & & & \\
\hline & AG & 143 (34.7\%) & $166(40.2 \%)$ & 0.43 & $0.901(0.670-1.214)$ & $0.871(0.676-1.131)$ \\
\hline & GG & $70(17.0 \%)$ & $4 \mathrm{I}(9.9 \%)$ & 0.01 & $\mathrm{I} .523(\mathrm{I} .124-2.23 \mathrm{I})$ & I.54I (I.II0-2.239) \\
\hline \multirow[t]{2}{*}{ Dominant } & AA & 199 (48.3\%) & 205 (49.8\%) & & & \\
\hline & AG/GG & $213(51.7 \%)$ & 207 (50.2\%) & 0.676 & I.23I (0.74I-I.43I) & $1.210(0.754-1.524)$ \\
\hline \multirow[t]{2}{*}{ Recessive } & AA/AG & $342(83.0 \%)$ & 371 (90.1\%) & & & \\
\hline & GG & $70(17.0 \%)$ & $41(9.9 \%)$ & 0.003 & 1.852 (1.226-2.798) & I.855 (I.22I-2.786) \\
\hline \multirow[t]{2}{*}{ Overdominant } & AG & 143 (34.7\%) & $166(40.2 \%)$ & & & \\
\hline & $\mathrm{AA} / \mathrm{GG}$ & $269(65.3 \%)$ & $246(59.8 \%)$ & 0.098 & $0.802(0.622-1.22 I)$ & $0.810(0.632-1.232)$ \\
\hline \multirow[t]{2}{*}{ Allele } & Allele A & $54 \mathrm{I}(65.7 \%)$ & $576(69.9 \%)$ & & & \\
\hline & Allele G & $283(34.3 \%)$ & 248 (30.1\%) & 0.065 & $1.213(0.947-1.522)$ & 1.247 (0.9I3-I.652) \\
\hline
\end{tabular}

Note: ${ }^{\mathrm{a}} \mathrm{OR}$ and $95 \% \mathrm{Cl}$ were adjusted by sex, age, smoking, and drinking.

Abbreviations: $\mathrm{OR}$, odds ratio; $\mathrm{Cl}$, confidence interval. 
Table 3 Association between rs895819 and clinical pathological characteristics in case group

\begin{tabular}{|c|c|c|c|c|c|c|c|c|}
\hline \multirow[t]{2}{*}{ Variables } & \multicolumn{3}{|c|}{ Genotype } & \multicolumn{2}{|l|}{$P$-value } & \multicolumn{2}{|c|}{ Allele } & \multirow[t]{2}{*}{$P$-value } \\
\hline & AA & AG & GG & [I] & [2] & A & G & \\
\hline \multicolumn{9}{|l|}{ Location } \\
\hline Right colon & 106 & 70 & 34 & & & 282 & 138 & \\
\hline Left colon & 46 & 32 & 19 & 0.851 & 0.451 & 124 & 70 & 0.432 \\
\hline Rectum & 47 & 41 & 17 & 0.29 & 0.727 & 135 & 75 & 0.475 \\
\hline \multicolumn{9}{|l|}{ Differentiation } \\
\hline High/moderate & 161 & 113 & 58 & & & 435 & 229 & \\
\hline Poor/undifferentiated & 38 & 30 & 20 & 0.667 & 0.228 & 106 & 70 & 0.193 \\
\hline \multicolumn{9}{|c|}{ Tumor-Node-Metastasis (TNM) stage } \\
\hline $\mathrm{I} / \mathrm{II}$ & 134 & 129 & 24 & & & 397 & 177 & \\
\hline III & 65 & 14 & 46 & $<0.001$ & $<0.001$ & 144 & 106 & 0.001 \\
\hline \multicolumn{9}{|l|}{ Cancer invasion } \\
\hline $\mathrm{TI} / \mathrm{T} 2$ & 42 & 28 & 20 & & & 112 & 68 & \\
\hline $\mathrm{T} 3 / \mathrm{T} 4$ & 157 & 115 & 50 & 0.73 & 0.202 & 429 & 215 & 0.273 \\
\hline \multicolumn{9}{|l|}{ Node metastasis } \\
\hline No/NI & 49 & 25 & 15 & & & 123 & 55 & \\
\hline $\mathrm{N} 2 / \mathrm{N} 3$ & 150 & 113 & 55 & 0.156 & 0.589 & 413 & 223 & 0.3 \\
\hline
\end{tabular}

Notes: [1]: genotype AG vs AA; [2]: genotype GG vs AA.

differentiation, and apoptosis and as a tumor oncogene or suppressor in cancer. ${ }^{24-27}$ Although it only accounts for a small proportion of human genome, it can regulate approximately one-third of human genes. ${ }^{28}$ Genetic variations of miRNA would affect its maturation and its binding capacity with mRNA-3'-untranslated region of the targeted gene, leading to dysfunctional regulation of its targeted gene. Recently, SNPs within miRNA were reported to be significantly associated with initiation, progression, and drug response in cancer. ${ }^{29-31}$ rs895819 is located in the terminal loop of pre-miRNA-27a; it would affect the secondary structure of pre-miR-27a and result in its abnormal expression of hsamiR-27a. So we speculate that rs 895819 within pre-miR-27a may be involved in CRC carcinogenesis.

In this study, our results showed that genotype GG frequency of the locus was significantly higher in cases than controls, suggesting that genotype GG of the locus was positively associated with CRC risk and it might be a genetic susceptible factor for CRC. Moreover, genotypes AG and $\mathrm{GG}$ and allele $\mathrm{G}$ of the locus were significantly associated with TNM-III stage, indicating that genotypes AG and GG and allele $\mathrm{G}$ were associated with $\mathrm{CRC}$ progression. The result of our study was also consistent with the results of recent studies conducted by $\mathrm{Cao}$ et $\mathrm{al}^{32}$ and Wang et $\mathrm{al}^{33}$ in Chinese population, but our study was more powerful to support a positive association between the locus and CRC in Chinese population. Wang et al reported that genotype GG and allele G were associated with an increased risk of metastasis; however, our study showed a positive association between allele $\mathrm{G}$ and allele $\mathrm{G}$ carrier (genotypes AG and GG) and invasion depth. However, Hezova et $\mathrm{al}^{34}$ and
Kupcinskas et $\mathrm{al}^{35}$ reported no association between them in European Caucasian population. The following reasons may account for this phenomenon. First of all, different genetic background may be one of the most important causes leading to the contradictory results. Second, $m i R-27 a$ have been reported as an oncogene in many kinds of cancer, including CRC; $9,10,36$ overexpression of hsa-miR-27a was detected both in SW480 and HT29 cell lines and in CRC biopsy; ${ }^{9,14}$ genotypes of rs895819 were significantly associated with hsa-miR-27a expression in CRC biopsy, ${ }^{32}$ suggesting that rs895819 within hsa-miR-27a was involved in CRC pathogenesis, and the locus could affect its expression. Third, higher hsa-miR-27a leads to lower expression of targeted PPAR- $\gamma, P L K 2$, and PI3K genes, ${ }^{10,12,37}$ contributing to the improvement of cell viability and colony formation and inhibition of the late apoptosis of CRC cell line.

\section{Conclusion}

In conclusion, our findings indicated that rs895819 within pre-miR-27a was involved in colorectal carcinogenesis and progression, genotype GG of the locus might be a susceptible factor for CRC, and allele $\mathrm{G}$ and allele $\mathrm{G}$ carrier (genotypes $\mathrm{AG}$ and GG) could predict CRC progression in north Chinese Han population.

\section{Acknowledgment}

This study was supported by the Health Bureau Science and Technology Foundation of Tianjin (No 2012KZ063).

\section{Disclosure}

The authors report no conflicts of interest in this work. 


\section{References}

1. Siegel RL, Miller KD, Jemal A. Cancer statistics, 2015. CA Cancer J Clin. 2015;65:5-29.

2. Chen W, Zheng R, Zeng H, Zhang S, He J. Annual report on status of cancer in China, 2011. Chin J Cancer Res. 2015;27:2-12.

3. Ying HQ, Sun HL, He BS, et al. Circulating vitamin D binding protein, total, free and bioavailable 25-hydroxyvitamin D and risk of colorectal cancer. Sci Rep. 2015;5:7956.

4. Linnekamp JF, Wang X, Medema JP, Vermeulen L. Colorectal cancer heterogeneity and targeted therapy: a case for molecular disease subtypes. Cancer Res. 2015;75:245-249.

5. Ramzi NH, Chahil JK, Lye SH, et al. Role of genetic and environment risk factors in the aetiology of colorectal cancer in Malaysia. Indian J Med Res. 2014;139:873-882.

6. Namazi A, Abedinzadeh M, Nourbaksh P, Neamatzadeh H. Association between the XRCC3 Thr241Met polymorphism and risk of colorectal cancer: a meta analysis of 5,193 cases and 6,645 controls. Asian Pac J Cancer Prev. 2015;16:2263-2268.

7. Grimm WA, Messer JS, Murphy SF, et al. The Thr300Ala variant in ATG16L1 is associated with improved survival in human colorectal cancer and enhanced production of type I interferon. Gut. [Epub ahead of print].

8. Ying H, Wang J, Gao X. CCL5-403, CCR5-59029, and Delta32 polymorphisms and cancer risk: a meta-analysis based on 20,625 subjects. Tumour Biol. 2014;35:5895-5904.

9. Chintharlapalli S, Papineni S, Abdelrahim M, et al. Oncogenic microRNA-27a is a target for anticancer agent methyl 2-cyano-3,11dioxo-18beta-olean-1,12-dien-30-oate in colon cancer cells. Int J Cancer. 2009;125:1965-1974.

10. Tian Y, Fu S, Qiu GB, et al. MicroRNA-27a promotes proliferation and suppresses apoptosis by targeting PLK2 in laryngeal carcinoma. BMC Cancer. 2014;14:678.

11. Salah Z, Arafeh R, Maximov V, et al. miR-27a and miR-27a* contribute to metastatic properties of osteosarcoma cells. Oncotarget. 2015;6: 4920-4935.

12. Li S, Li J, Fei BY, et al. MiR-27a promotes hepatocellular carcinoma cell proliferation through suppression of its target gene peroxisome proliferator-activated receptor gamma. Chin Med J (Engl). 2015;128:941-947.

13. Toden S, Okugawa Y, Buhrmann C, et al. Novel evidence for curcumin and boswellic acid induced chemoprevention through regulation of miR-34a and miR-27a in colorectal cancer. Cancer Prev Res (Phila). 2015;8(5):431-443.

14. Noratto GD, Jutooru I, Safe S, Angel-Morales G, Mertens-Talcott SU. The drug resistance suppression induced by curcuminoids in colon cancer SW-480 cells is mediated by reactive oxygen species-induced disruption of the microRNA-27a-ZBTB10-Sp axis. Mol Nutr Food Res. 2013;57:1638-1648.

15. Feng DD, Zhang H, Zhang $P$, et al. Down-regulated miR-331-5p and miR-27a are associated with chemotherapy resistance and relapse in leukaemia. J Cell Mol Med. 2011;15:2164-2175.

16. Li J, Wang Y, Song Y, Fu Z, Yu W. miR-27a regulates cisplatin resistance and metastasis by targeting RKIP in human lung adenocarcinoma cells. Mol Cancer. 2014;13:193.

17. Zhao X, Yang L, Hu J. Down-regulation of miR-27a might inhibit proliferation and drug resistance of gastric cancer cells. J Exp Clin Cancer Res. 2011;30:55.

OncoTargets and Therapy

\section{Publish your work in this journal}

OncoTargets and Therapy is an international, peer-reviewed, open access journal focusing on the pathological basis of all cancers, potential targets for therapy and treatment protocols employed to improve the management of cancer patients. The journal also focuses on the impact of management programs and new therapeutic agents and protocols on
18. Bai RP, Weng Y, Su LL, et al. Association of a pre-miR-27a polymorphism with cancer risk: an updated meta-analysis. Asian Pac J Cancer Prev. 2014;15:10107-10114.

19. Deng Y, Bai H, Hu H. rs 11671784 G/A variation in miR-27a decreases chemo-sensitivity of bladder cancer by decreasing miR-27a and increasing the target RUNX-1 expression. Biochem Biophys Res Commun. 2015; 458:321-327.

20. Ma JY, Yan HJ, Yang ZH, Gu W. Rs895819 within miR-27a might be involved in development of non small cell lung cancer in the Chinese Han population. Asian Pac J Cancer Prev. 2015;16:1939-1944.

21. Xiong XD, Luo XP, Cheng J, Liu X, Li EM, Zeng LQ. A genetic variant in pre-miR-27a is associated with a reduced cervical cancer risk in southern Chinese women. Gynecol Oncol. 2014;132:450-454.

22. Xu Q, He CY, Liu JW, Yuan Y. Pre-miR-27a rs895819A/G polymorphisms in cancer: a meta-analysis. PLOS ONE. 2013;8:e65208.

23. Xu J, Yin $\mathrm{Z}$, Shen $\mathrm{H}$, et al. A genetic polymorphism in pre-miR-27a confers clinical outcome of non-small cell lung cancer in a Chinese population. PLoS ONE. 2013;8:e79135.

24. Boon RA, Iekushi K, Lechner S, et al. MicroRNA-34a regulates cardiac ageing and function. Nature. 2013;495:107-110.

25. Purvis N, Bahn A, Katare R. The role of microRNAs in cardiac stem cells. Stem Cells Int. 2015;2015:194894.

26. Szafranski K, Abraham KJ, Mekhail K. Non-coding RNA in neural function, disease, and aging. Front Genet. 2015;6:87.

27. Taylor MA, Schiemann WP. Therapeutic opportunities for targeting microRNAs in cancer. Mol Cell Ther. 2014;2:1-13.

28. Zhong X, Coukos G, Zhang L. miRNAs in human cancer. Methods Mol Biol. 2012;822:295-306.

29. Dong Y, Yu J, Ng SS. MicroRNA dysregulation as a prognostic biomarker in colorectal cancer. Cancer Manag Res. 2014;6:405-422.

30. Rukov JL, Shomron N. MicroRNA pharmacogenomics: post-transcriptional regulation of drug response. Trends Mol Med. 2011;17: 412-423.

31. Shen R, Liu H, Wen J, et al. Genetic polymorphisms in the microRNA binding-sites of the thymidylate synthase gene predict risk and survival in gastric cancer. Mol Carcinog. 2015;54(9):880-888.

32. Cao Y, Hu J, Fang Y, Chen Q, Li H. Association between a functional variant in microRNA-27a and susceptibility to colorectal cancer in a Chinese Han population. Genet Mol Res. 2014;13:7420-7427.

33. Wang Z, Sun X, Wang Y, Liu X, Xuan Y, Hu S. Association between miR-27a genetic variants and susceptibility to colorectal cancer. Diagn Pathol. 2014;9:146.

34. Kupcinskas J, Bruzaite I, Juzenas S, et al. Lack of association between miR-27a, miR-146a, miR-196a-2, miR-492 and miR-608 gene polymorphisms and colorectal cancer. Sci Rep. 2014;4:5993.

35. Hezova R, Kovarikova A, Bienertova-Vasku J, et al. Evaluation of SNPs in miR-196-a2, miR-27a and miR-146a as risk factors of colorectal cancer. World J Gastroenterol. 2012;18:2827-2831.

36. Liu T, Tang H, Lang Y, Liu M, Li X. MicroRNA-27a functions as an oncogene in gastric adenocarcinoma by targeting prohibitin. Cancer Lett. 2009;273:233-242.

37. Liu G, Cao P, Chen H, Yuan W, Wang J, Tang X. MiR-27a regulates apoptosis in nucleus pulposus cells by targeting PI3K. PLoS ONE. 2013;8:e75251.

patient perspectives such as quality of life, adherence and satisfaction The manuscript management system is completely online and includes a very quick and fair peer-review system, which is all easy to use. Visit http://www.dovepress.com/testimonials.php to read real quotes from published authors. 